\title{
Modern Development Problems of Russian Healthcare: Part 2
}

\author{
V. N. Ivanov ${ }^{a}$ and A. V. Suvorov ${ }^{a, *, \dagger}$ \\ ${ }^{a}$ Institute for Economic Forecasting, Russian Academy of Sciences, Moscow, Russia \\ *e-mail:asuvor@ecfor.ru \\ Received May 31, 2021; revised June 7, 2021; accepted July 20, 2021
}

\begin{abstract}
The second part of the article (see the beginning in No. 6-2021) analyzes the negative consequences of the so-called health care optimization. It is shown that as a result of its implementation, the availability of medical care has decreased. A possible way to improve the territorial organization of medical services is considered. The effectiveness of the Russian health care system in the fight against the coronavirus pandemic was assessed.
\end{abstract}

DOI: $10.1134 / \mathrm{S} 1075700722010087$

"Optimization" of healthcare. The availability of medical care for the population of Russia, along with the commercialization of health care, has decreased as a result of a sharp reduction in the network of medical, primarily inpatient (hospital) organizations (Table 1). The reduction in the network was caused both by a largescale decrease in funding in the $1990 \mathrm{~s}$, and by the restructuring of medical care announced by the reformers in favor of its primary, outpatient level as the main direction of modernization of Russian health care.

It should be noted that the "curtailment" of the hospital network was carried out mainly due to the closure of hospitals in rural settlements and small towns. At the same time, there was no restructuring of medical care for the population of rural and small urban settlements: the number of outpatient clinics and primary health care organizations-first aidobstetric points (FOP) also-significantly decreased. As a result, according to the report of the Accounts Chamber, 17.5 thousand settlements with a population of less than 1.5 thousand inhabitants do not have units providing primary health care. More than 11.5 thousand settlements are located at a distance of more than $20 \mathrm{~km}$ from the nearest medical organization [1].

The established situation is largely explained by the fact that during the transition to the compulsory health insurance model, the assessment of the social effectiveness of health care (ensuring universal access to medical care) was sacrificed to the assessment of economic efficiency (the amount of costs per patient). In this case, small medical institutions began to be considered as an analog of small-scale production, which, of course, is inferior in profitability to largescale production. There has been, in fact, a thoughtless transition to purely market-based health manage-

\footnotetext{
${ }^{\dagger}$ Deceased.
}

ment mechanisms. Such a transition took place in relation to medical organizations in large cities; the enlargement of hospitals and clinics with a deterioration in their territorial accessibility for the population. It should be noted that this method of cost optimization began to dominate in other spheres of social life: the closure of small schools in rural areas and the consolidation of general education organizations in cities; the so-called renovation of the housing stock with the resettlement of residents from low-rise buildings with a large adjoining territory to "cheloveinniki" with compacted buildings. The observed trend is fraught not only with a deterioration in the living conditions of the population, but also with a potential risk of losing the territorial stability and integrity of the country. The apotheosis of such a policy, a kind of urban planning dystopia, is, in our opinion, the idea of reformatting the territorial resettlement population due to the large-scale growth of two dozen agglomerations, which will undoubtedly result in further depopulation of the vast territory of the country (see, for example, [2]).

As a result of the "optimization" of the network of medical organizations in many regions, a large gap has arisen in the provision of medical care to the population of large cities, especially regional centers, and the rest of the population of the regions. The scale of differentiation in the provision of the population with doctors and hospital beds can be judged by calculations based on statistics from the regions of the Central Federal District, presented in Table 2.

As for the restructuring of medical care in favor of its primary, outpatient level, the trend towards a reduction in the number of hospital beds is indeed characteristic of the United States and most Western European countries. In these countries, in conditions of a high level of funding, both in hospitals and in the outpatient department, a high level of equipment with 
Table 1. Indicators of the network of medical organizations

\begin{tabular}{|c|c|c|c|}
\hline Index & 1990 year & Oct. 2018 & 2018 to $1990, \%$ \\
\hline \multicolumn{4}{|l|}{ Number: } \\
\hline hospital organizations & 12762 & 5257 & 41 \\
\hline hospital beds, thous. & 2038 & 1173 & 58 \\
\hline ambulance stations (departments) & 3042 & 2276 & 75 \\
\hline outpatient polyclinic organizations & 21527 & 2028 & 94 \\
\hline first aid-obstetric points & 47700 & 35900 & 75 \\
\hline
\end{tabular}

diagnostic and therapeutic equipment has been achieved, the most modern medical technologies are widely used, the qualifications of medical workers are of a high standard, and a large and growing number of people are employed in health care. All this allows, firstly, concentrating the diagnosis and treatment of uncomplicated forms of diseases as much as possible in the less costly outpatient link, and secondly, intensifying the process of treatment in hospitals, thereby reducing the patient's stay in a hospital bed. Thus, a more efficient use of financial resources of health care is achieved while improving the quality of medical care.

In Russia, in conditions of low funding, the listed characteristics of health care systems are completely or partially absent. It is also important to note that in foreign countries, the process of restructuring health care systems did not have a "landslide" character, as was the case in Russia. In the United States, for example, for 1990-2018, the number of hospitals decreased by
$9 \%$, and the average annual rate of reduction in the number of hospital beds was less than $1 \%$ [3]. In Germany for 2000-2017, the number of hospitals decreased by $7 \%$, and the number of hospital beds by $12 \%$ [4]. At the same time, the reduction in hospital beds was accompanied not by a reduction in the number of hospital personnel, but by its growth. In the United States, for example, the number of people employed in the hospital sector increased between 1990 and 2018 by $43 \%$. This is due to the fact that, unlike other sectors of the economy modern healthcare technologies are not labor-saving.

It should be emphasized that the restructuring of medical care is justified only with a sufficiently high level of development of the primary, outpatient health care system and, in particular, its human resources. In Russia, the number of people employed in outpatient clinics was 564 thousands in 2018, or only 38 per 10 thousands of the population, while the German

Table 2. Provision of the population with doctors and hospital beds in the regions of the Central Federal District (2018)

\begin{tabular}{|c|c|c|c|c|c|c|}
\hline \multirow{2}{*}{$\begin{array}{l}\text { Region } \\
\text { (oblast) }\end{array}$} & Regional centers & $\begin{array}{c}\text { Other } \\
\text { settlements }\end{array}$ & $\begin{array}{c}\% \text { to } \\
\text { regional centers }\end{array}$ & Regional centers & $\begin{array}{c}\text { Other } \\
\text { settlements }\end{array}$ & $\begin{array}{c}\% \text { to } \\
\text { regional centers }\end{array}$ \\
\hline & \multicolumn{3}{|c|}{ doctors per 10000 people population } & \multicolumn{3}{|c|}{ beds for 10000 people population } \\
\hline Belgorod & 79.2 & 27.3 & 34 & 147.4 & 46.5 & 32 \\
\hline Bryansk & 70.1 & 24.5 & 35 & 131.9 & 45.5 & 35 \\
\hline Vladimir & 61.8 & 25.3 & 41 & 115.9 & 55.2 & 43 \\
\hline Voronezh & 85.4 & 84.7 & 99 & 115.9 & 55.2 & 48 \\
\hline Ivanovo & 73.9 & 23.2 & 31 & 134.5 & 45.9 & 34 \\
\hline Kaluga & 67.1 & 26.5 & 40 & 124.4 & 51.5 & 41 \\
\hline Kostroma & 40.4 & 27.8 & 56 & 98.1 & 79.6 & 83 \\
\hline Kursk & 79.4 & 27.5 & 35 & 98.1 & 76.8 & 78 \\
\hline Lipetsk & 60.8 & 27.5 & 45 & 96.6 & 69.6 & 72 \\
\hline Orel & 79.4 & 19.8 & 25 & 172.9 & 39.8 & 23 \\
\hline Ryazan & 81.7 & 23.9 & 29 & 119.7 & 41.2 & 34 \\
\hline Smolensk & 98.4 & 25.6 & 26 & 138.1 & 77.4 & 56 \\
\hline Tambov & 71.7 & 23.2 & 32 & 158.1 & 51.1 & 32 \\
\hline Tver & 87.5 & 22.8 & 26 & 157.2 & 66.7 & 42 \\
\hline Tula & 60.1 & 25.4 & 42 & 151.1 & 49.9 & 33 \\
\hline Yaroslavl & 77.6 & 30.0 & 39 & 123.3 & 67.4 & 55 \\
\hline
\end{tabular}


outpatient sector employed more than 130 out of 10 thousand inhabitants; in the United States it was more than $200[5,6]$.

Russia is characterized by a relatively high number of doctors (47.9 per 10 thousand people). However, there is an obvious shortage of doctors in the outpatient clinic sector. For example, the number of district therapists is only 35.4 thousand, or 3 per 10 thousand inhabitants [7]. This leads to an excessive workload of outpatient doctors, leaving them no time to increase the level of professional knowledge, which is necessary with the constant improvement of medical technologies, the rapid growth of the number of new drugs. As a result, the opportunities for outpatient doctors to choose the most effective methods for diagnosing and treating diseases identified in patients are reduced, which leads to the preservation of a high need for the hospitalization of patients, adequate diagnosis and treatment of which are not provided in the outpatient department.

The unsatisfactory state of the primary health care system leads to the spread of self-medication, stimulated by aggressive advertising of drugs. In this regard, the data of the Comprehensive Monitoring of the Living Conditions of the Population, conducted by Rosstat in 2018, according to which more than $40 \%$ of respondents did not go to outpatient medical institutions during the year if there was a need for medical care and preferred to be treated on their own [8]. This trend entails an increase in the number of complicated, advanced forms of diseases, often requiring emergency hospitalization, which, given the low territorial availability of hospital facilities, leads to an increase in hospital mortality. The number of patients who died in hospitals increased over 2005-2018 by 125 thousands, and the hospital mortality rate increased from 1.4 to $1.9 \%$. During the period under review, the total mortality rate of the population decreased by almost 500000 people.

Russian healthcare is also characterized by a lower ratio of the number of nurses to the number of doctors compared to most other countries. In 2018, it was only 2.2 in Russia, while in Germany it was 3.0, in France 3.1, in Australia 3.2, and the United States 4.0 [9]. As a result, the excessive workload of Russian doctors is also due to the fact that they are forced to perform work that may be entrusted to less qualified personnel. It is a well-known fact that many Russian outpatient doctors spend a significant part of their working time on filling out various kinds of medical documentation.

Thus, in spite of the fact that primary medical care is declared as a priority of the ongoing reform of the health care system, the conditions for providing citizens with timely and high-quality medical services in the outpatient link are currently limited. Summarizing all of the above, the opinion of the medical community that the ongoing optimization of the health care system, which consists in the rapid reduction of the hospital sector, should be recognized as wellgrounded, is, to say the least, ill-considered. The reformers, having created a myth about the redundancy of the hospital sector infrastructure in Russia, blindly copied the model of restructuring medical care used abroad, ignoring the structure of healthcare that was historically formed in our country and different from most foreign countries-the ratio of its outpatient and hospital sectors. They also ignore the experience of those countries, which are characterized by the existing structure of the health care system similar to that of Russia. Such a country is, in particular, Japan, the experience of the functioning of health care in which, in our opinion, deserves attention.

Analysis of Japanese health statistics shows the following [10]. Unlike most other countries, healthcare in Japan, as well as in Russian healthcare, has historically developed an obvious predominance of the hospital sector over the outpatient one. In Japan, however, despite the reduction in the number of hospitals (the hospital network decreased by only 7\% in 20052018 ) or the number of hospital beds (a decrease of $9 \%$ over the indicated period), Japan now ranks first in the world in terms of hospital bed availability (13.1 per 1000 population), significantly ahead of other countries (on average across countries of the OECD, it is 4.7 per 1000 people [10]).

In Japan, an extensive network of medium-sized municipal hospitals is preserved, ensuring their favorable territorial accessibility for residents of small settlements. About 3000 hospitals (36\% of the total) have less than 100 beds, and almost 1000 hospitals have less than 50 beds. On average, one hospital in Japan accounts for 16000 inhabitants and $45 \mathrm{~km}^{2}$ of territory. For comparison: in the United States, these figures are equal to 52 thousand inhabitants and $1500 \mathrm{~km}^{2}$, in Germany, respectively, 39 thousand and $185 \mathrm{~km}^{2}$.

The high availability of inpatient medical care in Japan provides additional opportunities for comprehensive examination and effective treatment in a hospital, not limited by strict standards for the length of stay in a hospital bed. According to this indicator, which is now almost universally considered as almost the main criterion for the effectiveness of the use of financial resources for health care, Japan is fundamentally different from other countries. The average number of days a patient stayed in a hospital bed in Japan was 28 days in 2017, or 3.6 times the OECD average. Let us recall that with a comparable level of per capita expenditures with a number of other developed countries, Japan is now the leader in the world in terms of life expectancy.

Despite the decline in the number of hospitals and hospital beds, the number of employees in the hospital sector in Japan is not decreasing, but growing. The number of doctors in the hospital sector is twice the number in the outpatient sector. At the same time, the hospital sector in Japan takes over some of the func- 
tions of the outpatient department. Outpatient reception of patients, for example, is conducted not only by outpatient, but also by hospital, doctors, since patients in Japan have the right to directly contact any doctor, regardless of his place of work and specialty.

The number of people employed in health care in Japan is growing mainly due to nursing staff, as well as paramedical personnel (physiotherapists, massage therapists, physiotherapy specialists, etc.) and engineering and technical workers serving modern medical equipment. The largest share in the structure of the employed falls on the average medical staff, the number of which in 2005-2018 increased by 28\%. As a result, with a relatively low number of doctors $(2.4$ per 1000 inhabitants, compared with 3.5 on average in OECD countries), Japan has the highest indicator of the ratio of the number of nurses to the number of doctors in the world, 4.7, (with 2.7 in average for OECD countries [9] and 2.2 in Russia). This frees doctors from performing work that does not require a correspondingly high qualification.

Providing patients with highly qualified medical care is also achieved due to the fact that Japanese health care is ranked first in the world in terms of modern medical equipment and one of the first places in terms of drug provision for the population. For example, the availability of computed tomographs in Japan is four times higher than the average for the OECD countries, and the availability of MRI devices is three times. Per capita drug expenditures in Japan are 1.5 times higher than the OECD average, with three-quarters of all expenditures accounted for by public funding (OECD average 58\%) [9].

Returning to the consideration of the problem of optimization of medicine in Russia, it should be noted that in 2010 the so-called "May decrees" of the President of the Russian Federation, adopted in 2012, became an incentive to further reduce the hospital sector. According to these decrees, by 2018 , the average salary of doctors was to be increased to $200 \%$, and that of middle and junior medical personnel to $100 \%$ of the average salary in the region's economy. The need to raise wages in health care was fully justified: the average wage in the industry was in 2012 only $77 \%$ of the average wage in the economy. At the same time, the implementation of the May decrees required an adequate increase in funding for medical organizations, which was not done. As a result, the desire of regional leaders to report on the implementation of the May decrees led to the fact that in 2012-2018, 915 hospital organizations were cut, and the total number of hospital beds decreased by 159 thousand, or $14 \%$. Optimization of the hospital sector was carried out in large cities, including the capital. In Moscow, from 2012 to 2018,58 out of 211 hospital organizations were cut, and the number of hospital beds decreased by 30 thousand, or $36 \%$.
Summarizing the above, we can draw the following conclusion: ensuring the universal availability of qualified medical care, including its territorial accessibility, requires an increase in the network of medical organizations, both outpatient and hospital sectors at the municipal level. Their staff should be strengthened, the material and technical base of these organizations should be significantly improved, and they should be equipped with modern medical equipment. At the lowest territorial level, especially in areas with a dispersed population, it seems expedient not to restore, as is the case now, the network of FOP, which are an outdated form of primary health care, but to deploy a network of general practitioners' offices. The tasks of the latter, in addition to performing the functions of FOP, should be both primary diagnostics and the management of chronic patients that do not require treatment in hospitals.

Thus, not only an increase in funding is required, but also a serious modernization of the territorial organization of Russian health care. As a result, one should expect a significant increase in the number of people employed in health care, which is also one of the important factors in reducing tension in the labor market. The growth of employment in health care fully corresponds to the global trend in the conditions of automation of production processes in the real sector. Over the period from 2000 to 2017, on average across OECD countries, the number of people employed in health care and social services increased from 8 to $10.1 \%$ of the total number of people employed in the economy, and in countries such as the United Kingdom, Germany, the United States, France, and Japan, it increased to $12-14 \%$ [9]. In Russia, as a result of optimization, the opposite trend was observed: in the total number of people employed in the economy, the number of people employed in health care and social services decreased from $6.8 \%$ in 2000 to $6.0 \%$ in 2019.

Lessons learned from the COVID-19 pandemic. The coronavirus pandemic has become a serious test for Russian health care. To assess how successfully it coped with this challenge, it is necessary to assess the scale of the increase in the mortality rate of the Russian population due to the pandemic. According to Rosstat, 162.4 thousand deaths were associated with coronavirus infection in 2020, including 86.5 thousand cases identified as directly caused by coronavirus. Mortality associated with COVID-19, according to Rosstat, was significantly higher than that registered by the operational headquarters of the government (57 thousand), but half the officially registered increase in mortality in 2020 compared to 2019 (323.8 thousands). Such an increase in mortality has not been observed in Russia for almost 20 years. As a result of this increase, the average life expectancy decreased, according to preliminary data, by more than two years and amounted to 71.1 years in 2020 , returning to the level of 2014. 
Judging by the size of the increase in mortality in 2020 , it can be assumed that Russian health care was ineffective in the fight against COVID-19. This is, however, only a preliminary hypothesis that requires a more detailed analysis, while comparing the situation in Russia with other countries is of absolute interest in this regard, since the coronavirus pandemic has become a serious challenge for the health care of all countries.

To carry out such an analysis, it is necessary, first of all, to move from the indicator of the annual increase in mortality to the indicator of excess mortality, i.e., its increase in comparison with the expected, usually calculated as the average value of this indicator over several previous years. At the same time, the comparison should be made only in relation to the time period during which the outbreak of COVID-19 is recorded, and similar time periods on average over previous years. We calculated the excess mortality rate as the difference between the mortality rate for the period from April 2020 (when the first 50 deaths associated with COVID-19 were recorded in Russia) to January 2021 and the average mortality rate for the corresponding time periods of the previous five years. This method of calculation corresponds to the methodology adopted in other countries.

According to our calculations, over the specified period, excess mortality during the coronavirus pandemic in Russia amounted to 350900 deaths, or 240 cases per 100000 people. Comparison of this indicator with data for other countries indicates that in Russia the damage from COVID-19 was significantly greater than in many developed countries. The excess mortality rate in Russia was more than two times higher than in Austria, the Netherlands, France and Sweden, more than three times higher than in Germany, five times higher than in Israel and more than ten times higher than in Denmark and Finland. Attention is also drawn to the fact that in Norway, South Korea and Japan, it was generally possible to avoid an increase in the mortality rate of the population (Table 3 ). It is interesting to note in this regard that South Korea, like Japan, is significantly ahead of other countries in terms of the provision of hospital beds, and Norway is the undisputed world leader in terms of employment in health care (health care and social security account for $20 \%$ of total employment in the Norwegian economy [9]).

The high excess mortality in Russia is explained, of course, not only by the inefficiency of the Russian health care system. The country's authorities are also responsible for the current situation. Firstly, entry to Russia from countries where the epidemic began was not closed on time. No official recommendation was given to refuse travel to these countries. Despite the fact that in February 2020 cases of infection with COVID-19 were officially registered in many European countries, and quarantine was introduced in 11 regions of Italy, the Russian authorities stopped air traffic with European countries only on March 27. In other words, before that time, tens of thousands of potential virus carriers returned to Russia from Europe: in total in the EU countries in the 1st quarter of 2020, more than a million Russian tourists visited, including 180 thousand in Italy [12]. At the same time, neither testing for coronavirus, nor quarantine measures for those arriving from countries where the epidemic began, were carried out. As a result, if the first patient diagnosed with COVID-19 (who returned from Italy) was registered in Russia on March 2, then by March 27, when the border was closed, the number of cases was already about two thousand.

In addition, no measures were taken to prevent the spread of infection from Moscow, which is the country's main gateway, to other regions. As a result, at the beginning of the coronavirus epidemic, cases of illness and death from COVID-19 were recorded mainly in Moscow, and subsequently the infection spread throughout the country.

Not only the majority of the population, but also many medical workers who had direct contact with those infected with COVID-19, were not provided with personal protective equipment in time. In general, a unified state system for managing antiepidemic measures based on the recommendations of leading experts has not been created. The functions of introducing specific measures to combat coronavirus infection were transferred to the heads of the regions.

The Russian health care system also turned out to be unprepared for a massive epidemic. In the course of the optimization of health care, the network of infectious diseases hospitals was curtailed, and the number of beds for infectious patients decreased by more than 80 thousand. As a result, the explosive increase in the incidence of coronavirus infection quickly led to a shortage of infectious beds. For the treatment of patients with COVID-19, other hospitals that remained after the optimization had to be redesigned. In Moscow, for example, in total, more than 50 hospitals were redesigned, including hospitals of federal medical research centers that provide high-tech care to patients with the most complex pathologies from all regions of the country.

Due to the shortage of hospitals in the regions, hospitalization of patients with COVID-19 could be carried out only in repurposed hospitals in large cities, mainly in regional centers. The need to transport patients to these hospitals often over a distance of more than $100 \mathrm{~km}$ has led to a decrease in the availability of emergency medical care for the population of rural settlements and small towns. The waiting time for the arrival of an ambulance for many patients began to be calculated in hours or even days.

The transfer of medical workers from other hospitals and outpatient organizations to work in COVID hospitals, including those with no experience of work- 
Table 3. Excess mortality rates by country

\begin{tabular}{|c|c|c|c|}
\hline Country & Time period & $\begin{array}{l}\text { Number of cases } \\
\text { redundant mortality }\end{array}$ & $\begin{array}{l}\text { The number of cases } \\
\text { in per } 100 \text { thousand population }\end{array}$ \\
\hline Peru & $01.04 .2020-28.02 .2021$ & 116480 & 355 \\
\hline Mexico & $29.03 .2020-02.01 .2021$ & 307770 & 257 \\
\hline Russia & $01.04 .2020-31.01 .2021$ & 350900 & 240 \\
\hline South Africa & $12.04 .2020-20.02 .2021$ & 128560 & 219 \\
\hline Poland & $30.03 .2020-14.02 .2021$ & 79300 & 207 \\
\hline Portugal & $23.03 .2020-07.02 .2021$ & 20720 & 201 \\
\hline United Kingdom & 14.03.2020-19.02.2021 & 124170 & 187 \\
\hline Spain & $04.03 .2020-25.02 .2021$ & 82780 & 177 \\
\hline Belgium & $16.03 .2020-07.02 .2021$ & 20210 & 177 \\
\hline United States & 08.03.2020-06.02.2021 & 545420 & 168 \\
\hline Hungary & $06.04 .2020-24.01 .2021$ & 14330 & 147 \\
\hline Netherlands & $16.03 .2020-21.02 .2021$ & 20490 & 118 \\
\hline France & $11.03 .2020-04.03 .2021$ & 70320 & 109 \\
\hline Sweden & $16.03 .2020-14.02 .2021$ & 11170 & 108 \\
\hline Austria & $23.03 .2020-14.03 .2021$ & 9340 & 105 \\
\hline Germany & $16.03 .2020-14.02 .2021$ & 63760 & 77 \\
\hline Israel & $30.03 .2020-07.02 .2021$ & 4020 & 43 \\
\hline Denmark & $23.03 .2020-21.02 .2021$ & 1160 & 20 \\
\hline Finland & $06.04 .2020-31.01 .2021$ & 820 & 15 \\
\hline South Korea & $02.03 .2020-03.01 .2021$ & -1120 & -2 \\
\hline Norway & $30.03 .2020-14.02 .2021$ & -240 & -4 \\
\hline Japan & 01.03.2020-31.12.2020 & -7040 & -6 \\
\hline
\end{tabular}

Source. From data of [11].

ing with infectious patients, led to both a decrease in the effectiveness of treatment of patients with coronavirus and a significant reduction in the possibility of necessary medical care for other patients. To compensate for the personnel deficit, an attempt was even made to mobilize senior students of medical universities who did not have practical skills in working with patients.

In the pharmacy network of most regions, a shortage of many drugs has arisen as a result of both the growth of self-medication and the media policy on advertising certain "miraculous" drugs. The often inadequate measures taken by the leadership of the regions to combat coronavirus infection have led to an increase in socio-psychological tension, leading to an increase in the incidence in the population.

All of the above, apparently, caused such a high mortality rate in Russia during the coronavirus pandemic. At the same time, if we consider the data on the number of deaths directly caused by coronavirus given by Rosstat as reliable, it should be concluded that the high mortality rate in the period under review was due not so much to COVID-19 itself, but rather to the imperfection of the entire medical care system in the country as a result of underfunding of health care. and taking inadequate measures to reform it. In this regard, it is imperative to implement a fundamentally new strategy for the development of Russian healthcare.

\section{REFERENCES}

1. Public report of the All-Russian Popular Front. http://www.robprzrf.ru/news/?SECTION_ID=91\& ELEMENT_ID=5769. Cited March 11, $20 \overline{2} 1$.

2. Discussion between Aleksey Kudrin and Sergei Sobyanin on the role of agglomerations in the future of the country's economy. https://civil-forum.ru/news/diskussiya-alekseya-kudrina-i-sergeya-sobyanina-o-roliaglomeratsiy-v-budushchem-ekonomiki-strany-vi.html. Cited March 11, 2021.

3. F. Michas, Number of all hospital beds in the U.S. 1975-2019, 2021. https://www.statista.com/statistics/185860/number-of-all-hospital-beds-in-the-us . Cited March 12, 2021.

4. F. Michas, Hospital beds in Germany 2000-2017, 2020. https://www.statista.com/statistics/557270/hospitalbeds-in-germany/. Cited March 12, 2021. 
5. Health care employment projections, 2014-2024: an analysis of Bureau of Labor Statistics Projections by Setting and by Occupation School of Public Health University at Albany, State University of New York, 2016. https://www.chwsny.org/wp-content/uploads/ 2016/04/BLS-Health-Care-Employment-Projections_ 2016.pdf. Cited March 17, 2021.

6. Health personnel: Germany, years, facilities, sex. https://www-genesis.destatis.de/genesis//online?operation $=$ table $\&$ code $=23621-0001 \&$ bypass $=$ true $\&$ leve lindex $=0 \&$ levelid $=1616658138620 \#$ abreadcrumb. Cited March 17, 2021.

7. Resources and Activities of Medical Healthcare Organizations. Medical Personnel 2018: Statistical Handbook (Ministry of Health of the Russian Federation, 2019) [in Russian].
8. Comprehensive Monitoring of the Living Conditions of the Population (Rosstat, Moscow, 2019) [in Russian].

9. Health at a Glance 2019: OECD Indicators (Organisation for Economic Co-operation and Development, Paris, 2019).

10. Handbook of health and welfare statistics, 2019. https://www.mhlw.go.jp/english/database/db-hh/22.html. Cited March 21, 2021.

11. Tracking covid-19 excess deaths across countries. https://www.economist.com/graphic-detail/coronavirus-excess-deaths-tracker. Cited March 21, 2021.

12. Number of outbound tourist trips of Russian citizens to foreign countries in the 1st quarter of 2020. https://www.gks.ru/free_doc/new_site/business/torg/ tur/tab-tur1-2.htm. Cited March 21, 2021. 